\title{
Notes on the vocalizations of Cliff Flycatcher (Hirundinea ferruginea)
}

Peter Boesman

In the following we briefly analyze and compare voice of the different races of Cliff Flycatcher (Hirundinea ferruginea). We also try to quantify the extent of any vocal differences using the criteria proposed by Tobias et al. (2010), as a support for taxonomic review.

We have made use of sound recordings available on-line from Xeno Canto (XC) and Macaulay Library (ML).

Song of all races is structurally very similar, a long note followed by a trilled series of notes (which highly vary in number) (Fig. 1).

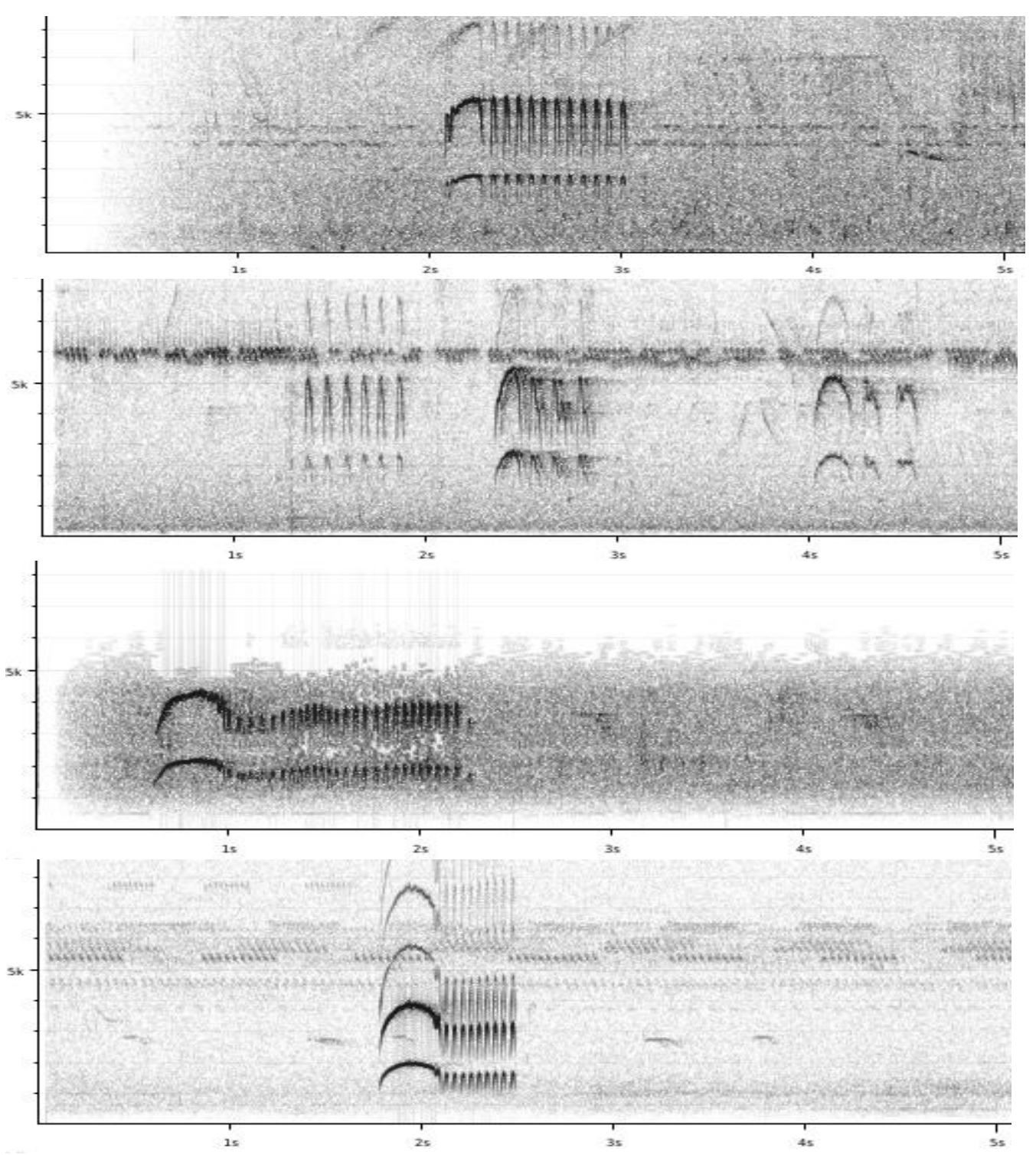

Figure 1: from top to bottom: example of song of race sclateri, ferruginea, pallidior and bellicosa. 

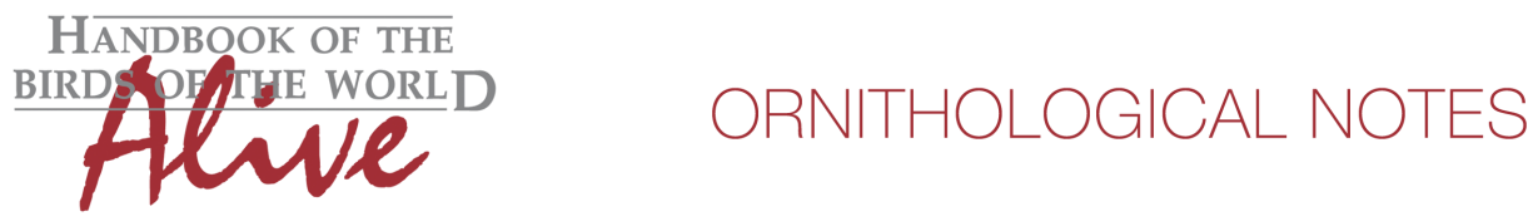

There are however some notable differences:

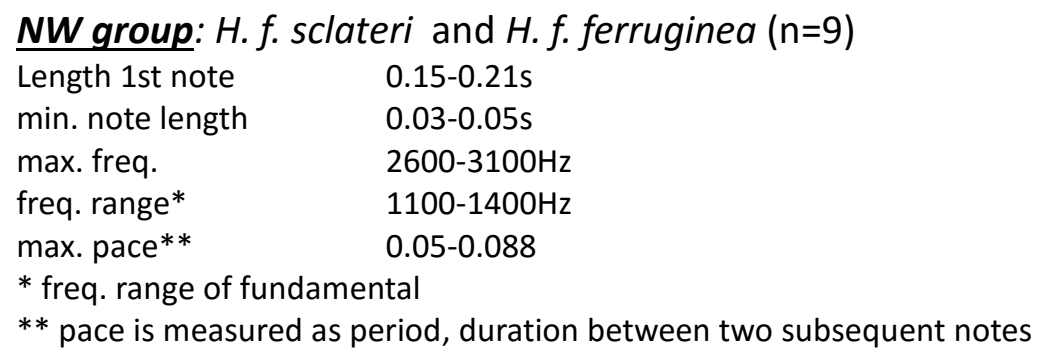

SE group: H. f. pallidior and H. f. bellicosa $(n=9)$

\begin{tabular}{ll}
\hline Length 1st note & $0.20-0.37 \mathrm{~s}$ pallidior and $0.28-0.40 \mathrm{~s}$ bellicosa \\
min. note length & $0.033-0.040 \mathrm{~s}$ \\
max. freq. & $1810-2400 \mathrm{~Hz}$ \\
freq. range & $600-1000 \mathrm{~Hz}$ \\
max. pace & $0.041-0.055$
\end{tabular}

Also: in about all samples of SE group the first long note seems to be connected to the first note of the trill, while in the NW group, there is a very clear separation between first long note and subsequent notes.

Differences are thus:

Song of pallidior/bellicosa is lower-pitched (score 2-3), has a smaller frequency range (score 2 ), reaches a faster pace (score 1-2) and has a longer start note (score 1-2).

When applying Tobias criteria we obtain as a total vocal score about 4.

This note was finalized on 3rd July 2015, using sound recordings available on-line at that moment. We would like to thank in particular the many sound recordists who placed their recordings for this species on XC and ML.

\section{References}

Tobias, J.A., Seddon, N., Spottiswoode, C.N., Pilgrim, J.D., Fishpool, L.D.C. \& Collar, N.J. (2010). Quantitative criteria for species delimitation. Ibis 152(4): 724-746.

\section{Recommended citation}

Boesman, P. (2016). Notes on the vocalizations of Cliff Flycatcher (Hirundinea ferruginea). HBW Alive Ornithological Note 126. In: Handbook of the Birds of the World Alive. Lynx Edicions, Barcelona. (retrieved from http://www.hbw.com/node/932049 on 5 August 2016). 